\title{
Visual Prompt Poster for Promoting Patient-Physician Conversations on Weight Loss
}

\author{
Gillian S. Stephens, MD, MSc ${ }^{1}$ \\ Stephanie E. Blanken, $M D^{2}$ \\ K. Allen Greiner, $M D, M P H^{3}$ \\ Heidi S. Cbumley, $M D^{3}$
}

'Department of Community and Family Medicine, Saint Louis University, St Louis, Missouri

${ }^{2}$ Department of Cardiothoracic Surgery, St Francis Health Center, Topeka, Kansas

${ }^{3}$ Department of Family Medicine, University of Kansas Medical Center, Kansas City, Kansas

mit

MORE ONLINE

www.annfammed.org
Conflicts of interest: none reported

\section{CORRESPONDING AUTHOR}

Gillian S. Stephens, MD, MSc Department of Community and Family Medicine

Saint Louis University 1402 S Grand Blvd St Louis, MO 63104 gstephe1@slu.edu

\begin{abstract}
PURPOSE This study investigated the effect of a simple visual prompt in the form of a poster on the occurrence of patient-physician weight loss conversations during routine office encounters in a primary care outpatient clinic.
\end{abstract}

METHODS We conducted a 2-phase study in a family medicine residency program outpatient clinic in August and September 2006. During the first phase, lasting 5 days, we surveyed all nonpregnant adult patients (preintervention group) about weight loss. We then implemented a visual prompt in the form of a colorful poster (11 x 17 inches) in both English and Spanish. The poster read "Do you want to lose weight? Ask your doctor today!" and included a picture of a bathroom scale. During the second phase, also lasting 5 days, we again surveyed all nonpregnant adult patients (postintervention group).

RESULTS Analyses were based on 283 patients in the preintervention group and 386 patients in the postintervention group. The mean body mass index, obtained from medical records, did not differ significantly between groups (31 vs $32 \mathrm{~kg} / \mathrm{m}^{2}$, respectively). Fully $60 \%$ of patients in the postintervention group recalled seeing the poster during their visit; however, the percentage of patients who reported discussing weight loss with their physician did not differ between the preintervention and postintervention groups overall (29\% vs $27 \%)$, among the two-thirds of patients who wanted to lose weight ( $26 \%$ vs $23 \%$ ), or when only postintervention patients who saw the poster were included in the comparison (29\% vs $29 \%$ ). The large majority of patients in both groups who had such discussions-82\% and $77 \%$-indicated that they found them useful; the difference between groups was not significant.

CONCLUSION A simple visual prompt in the form of a poster directed at patients did not increase the occurrence of conversations between patients and their physicians about weight loss.

Ann Fam Med 2008;6(suppl 1):s33-s36. DOI: 10.1370/afm.780.

\section{INTRODUCTION}

0 ixty-five percent of the adult US population is overweight (body mass index $\left.[\mathrm{BMI}]=25.0-29.9 \mathrm{~kg} / \mathrm{m}^{2}\right)$ or obese $\left(\mathrm{BMI} \geq 30.0 \mathrm{~kg} / \mathrm{m}^{2}\right){ }^{1}$ Obesity is the second leading cause of preventable death in the United States, ${ }^{2}$ yet primary care physicians are not discussing weight loss with their patients. ${ }^{3}$

Patient-initiated discussions about weight loss are more likely to lead to a combination of advice and assistance than are physician-initiated discussions. ${ }^{4}$ In addition, patients are more likely to try to lose weight if they have been advised to do so by their health care professional. ${ }^{5}$ Few patients schedule appointments specifically to discuss weight loss, ${ }_{1}^{5}$ and multiple factors have been found to impede the quality and length of patient-physician weight loss discussions in the primary care setting. ${ }^{6-9}$ 
Since the early 20th century, posters have been used to bring attention to public health issues and to promote behavior change. ${ }^{10,11}$ Studies evaluating the influence of signs on behavior change have had mixed results,,$^{12-15}$ and it remains unclear if posters displayed in primary care offices are successful in promoting patient behavior change.

Our study aimed to determine if a simple visual prompt, in the form of a poster directed at patients in a primary care office, might increase the occurrence of weight loss conversations between patients and their physicians.

\section{METHODS}

\section{Setting and Participants}

We assessed a practice-level intervention during a 2phase study in a family medicine residency program outpatient clinic. The study took place over a 10 -day period in August and September 2006. The physicians in the clinic were board-certified family physicians (faculty) and residents in all 3 years of training. We did not collect identifiers or demographics of individual patients or physicians. The study was approved by the University of Kansas Medical Center Human Subjects Committee.

\section{Intervention and Study Groups}

During the study's first phase, which lasted 5 days, we surveyed all nonpregnant patients older than 18 years (preintervention group) in writing (English and Spanish) as they exited the clinic immediately following their office visit. The patients were asked "Do you want to lose weight?" and "Did you discuss weight loss with your doctor today?" and "Did you find the information useful?" Response choices were yes, no, and not applicable.

We then implemented an intervention by displaying a simple visual prompt in the form of a colorful poster measuring $11 \mathrm{x} 17$ inches. The poster, printed in both English and Spanish versions, read "Do you want to lose weight? Ask your doctor today!" and included an illustration of a bathroom scale (see the Supplemental Figure, available online-only at http:// www.annfammed.org/cgi/content/full/6/suppl_1/ s33/DC1). The poster was displayed in every examination room, above the clinic's digital scales, across from the vitals stations, and in all public areas throughout the clinic.

During the second phase of the study, which also lasted 5 days, we again surveyed in writing all nonpregnant adult patients (postintervention group) as they exited the clinic immediately following their office visit. We used the above 3 questions as well as a fourth question, "Did you see the weight loss poster today?" Response choices were yes, no, and not applicable.

\section{Analysis}

We compared the distribution of BMI (ascertained from electronic medical records) between the preintervention and postintervention groups using an independent sample $t$ test as a measure of equivalency between the groups. We compared responses on the questionnaires between groups using a nonparametric test for 2 independent samples, the Mann-Whitney $U$ test.

\section{RESULTS}

There were 283 and 386 patients in the preintervention and postintervention groups, respectively. A total of 5 patients in the preintervention and 7 patients in the postintervention groups declined to complete the questionnaire and were included in the analyses.

The preintervention and postintervention groups were equivalent with respect to mean BMI (31 vs $32 \mathrm{~kg} / \mathrm{m}^{2}$, respectively $\left.P=.21\right)$. The proportion with a BMI of at least $25 \mathrm{~kg} / \mathrm{m}^{2}$ (indicating that they were overweight or obese) was $73 \%$ in the preintervention group and $75 \%$ in the postintervention group. The proportion of patients desiring to lose weight did not differ significantly between groups (65\% vs $67 \%, P=.63$ ) (Table 1 ).

Table 1. Patient Responses to Survey Questions Before and After Poster Intervention in the Clinic

\begin{tabular}{|c|c|c|c|c|c|c|c|}
\hline \multirow[b]{2}{*}{ Question } & \multicolumn{3}{|c|}{ Preintervention Group } & \multicolumn{3}{|c|}{ Postintervention Group } & \multirow[b]{2}{*}{$P$ Value* } \\
\hline & n & $\begin{array}{c}\text { Yes } \\
\text { No. (\%) }\end{array}$ & $\begin{array}{c}\text { No } \\
\text { No. (\%) }\end{array}$ & n & $\begin{array}{c}\text { Yes } \\
\text { No. (\%) }\end{array}$ & $\begin{array}{c}\text { No } \\
\text { No. (\%) }\end{array}$ & \\
\hline 1. Do you want to lose weight? & 283 & $185(65)$ & $93(33)$ & 386 & $259(67)$ & $120(31)$ & .63 \\
\hline 2. Did you discuss weight loss with your doctor today? & 283 & $81(29)$ & $197(70)$ & 386 & $103(27)$ & $276(71)$ & .59 \\
\hline 3. Did you find the information useful? & 78 & $64(82)$ & $12(15)$ & 103 & $79(77)$ & $9(9)$ & .23 \\
\hline 4. Did you see the weight loss poster today? & NA & NA & NA & 386 & $231(60)$ & $148(38)$ & NA \\
\hline
\end{tabular}


There was no significant difference in the percentage of patients who both wanted to lose weight and discussed weight loss with their physician between the preintervention and postintervention groups (26\% vs $23 \%, P=.41$. Among those patients who had weight loss conversations with their physicians, the perceived usefulness of information did not differ between groups $(82 \%$ vs $77 \%, P=.23)$ (Table 1 ).

Fully $60 \%$ of patients in the postintervention group reported seeing the poster during their visit (Table 1). There was no difference, however, between the percentages of preintervention and postintervention patients who reported having weight loss discussions overall $(29 \%$ vs $27 \%, P=.59$ ), or between the percentage of preintervention patients who discussed weight loss and the percentage of postintervention patients who both saw the poster and discussed weight loss ( $29 \%$ vs $29 \%, P=.84)$.

Given our null findings for differences in the occurrence of weight loss conversations between groups, we conducted a power analysis. We found that with the number of participants in our study, we had a greater than $95 \%$ power to detect a $20 \%$ difference in the reported rate of weight loss conversations between the preintervention and postintervention groups. In addition, we had a greater than $80 \%$ power to detect a $10 \%$ difference in the reported rate of such conversations between the groups.

\section{DISCUSSION}

We found that in a primary care outpatient clinic, a simple visual prompt in the form of a poster did not increase the proportion of patients reporting that they wanted to lose weight or the proportion of patients reporting that patient-physician conversations about weight loss took place. Large percentages of patients in this clinic, however, were interested in losing weight (66\%) and noticed the poster (60\%).

A review of the BMI data showed that about $75 \%$ of the study patients visiting the clinic were overweight or obese, compared with the $65 \%$ nationwide prevalence. This result is consistent with findings from other work on obesity in primary care, which has indicated that obese patients have more comorbidities (eg, hypertension, coronary artery disease, diabetes mellitus, and/or sleep apnea) for which they seek medical care. ${ }^{1}$

A total of 281 patients ( $42 \%$ of those surveyed) reported an interest in weight loss but did not discuss it with their physician during a routine office visit. This represents a large number of missed opportunities to influence behavior change. The 5 A's_-ask, assess willingness to change, advise, assist, and arrange follow-up-are a familiar approach to assist patients with smoking cessation. ${ }^{16}$ This model calls for repetition and reevaluation at every medical encounter. Similar techniques could be adapted to promote weight loss among overweight and obese patients, as has been called for by the US Preventive Services Task Force. ${ }^{17}$

One limitation to our study is the possibility that our null findings were simply due to inadequacy of the poster. We could have performed pretesting to determine whether patients had a positive or negative response to the poster and to determine physician attitudes toward the poster. Additional limitations to our study were that we did not determine whether the patient or the physician initiated the weight loss conversation, whether the poster motivated patients to initiate the discussion, or whether physicians were skilled at discussing weight loss with their patients.

Our simple poster prompt may prove effective at promoting weight loss conversations if the poster was part of a longer, multifaceted study that would include resources such as physician education, prompts in the electronic medical record system, printed materials, computer-based information, audiovisual materials, nutritional counseling, support groups, and exercise classes for patients.

To read or post commentaries in response to this article, see it online at http://www.annfammed.org/cgi/content/full/6/suppl_1/s33.

Submitted April 18, 2007; submitted, revised, August 28, 2007; accepted September 23, 2007.

Key words: Poster; visual prompt; obesity; overweight; weight loss; motivation; behavior change; physician-patient relations; office visits; primary care

Funding support: Funding provided by Health Resources and Services Administration grant D58HP05156.

Acknowledgments: The authors express their gratitude to the Department of Family Medicine clinic staff for their cooperation. We are indebted to Travis R. Langner, BS, for assistance with the design of the poster, John E. Delzell, MD, MSPH, for assistance with BMI data collection, and Aaron G. Epp, MA, for technical assistance.

\section{References}

1. National Institutes of Health. Clinical Guidelines on the Identification, Evaluation, and Treatment of Overweight and Obesity in Adults-The Evidence Report. Rockville, MD: National Institutes of Health; 1998.

2. Mokdad AH, Marks JS, Stroup DF, et al. Actual causes of death in the United States, 2000. JAMA. 2004;291(10):1238-1245.

3. Abid A, Galuska D, Khan LK, et al. Are healthcare professionals advising obese patients to lose weight? A trend analysis. Med Gen Med. 2005;7(4):10.

4. Flocke SA, Clark A, Schlessman K, et al. Exercise, diet, and weight loss advice in the family medicine outpatient setting. Fam Med. 2005;37(6):415-421.

5. Scott JG, Cohen D, DiCicco-Bloom B, et al. Speaking of weight: how patients and primary care clinicians initiate weight loss counseling. Prev Med. 2004;38(6):819-827. 
6. Kushner RF. Barriers to providing nutrition counseling by physicians: a survey of primary care practitioners. Prev Med. 1995;24(6):546-552.

7. Bowerman S, Bellman M, Saltsman P, et al. Implementation of a primary care physician network obesity management program. Obes Res. 2001;9(Suppl 4):321S-325S.

8. Bramlage $\mathrm{P}$, Wittchen HU, Pittrow D, et al. Recognition and management of overweight and obesity in primary care in Germany. Int J Obes Relat Metab Disord. 2004;28(10):1299-1308.

9. Ely AC, Greiner KA, Born W, et al. Concordance of patient-physician obesity diagnosis and treatment beliefs in rural practice settings. J Rural Health. 2006;22(4):364-366.

10. Helfand WH. To Your Health: An Exhibition of Posters for Contempo rary Public Health Issues. Rockville, MD: National Library of Medicine; 2003.

11. National Library of Medicine. Visual Culture and Public Health Posters [Web site]. http://www.nlm.nih.gov/exhibition/visualculture/ vchome.html. Accessed Feb 20, 2006.
12. Cox BS, Cox AB, Cox DJ. Motivating signage prompts safety belt use among drivers exiting senior communities. J Appl Behav Anal. 2000;33(4):635-638.

13. Badland HM, Schofield GM. Posters in a sample of professional worksites have no effect on objectively measured physical activity. Health Promot J Aust. 2005;16(1):78-81.

14. Ross MW, Chatterjee NS, Leonard L. A community level syphilis programme: outcome data from a controlled trial. Sex Transm Infect. 2004;80(2):100-104

15. Montazeri A, Sajadian A. Do women read poster displays on breast cancer in waiting rooms? J Public Health (Oxf). 2004;26(4):355-358.

16. Fiore MC, Bailey WC, Cohen S. Treating Tobacco Use and Dependence: Clinical Practice Guideline. Rockville, MD: US Department of Health and Human Services, Public Health Service; 2000. AHRQ publication 00-0032

17. US Preventive Services Task Force. Screening for obesity in adults: recommendations and rationale. Ann Intern Med. 2003;139(11) 930-932. 